\title{
Naduridt an ben Lefer.
}

Bum erfrentral erfacien Ratban ber şeife 1779 , auf Sorausbesallang; Daber obne Tamen cinés Serlegers, und olyne Drutceut, bló, mit ienter

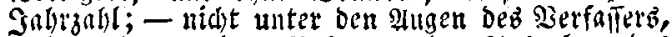

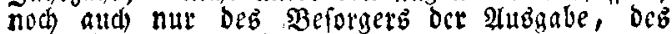

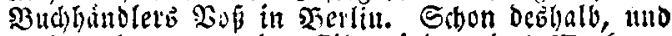
noch mehte wegen Det Sile, illdem Dab gagerf zut Sitermeffe fertis fevn muste, war es unmoglida,

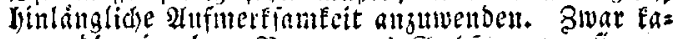
then bie einzeltent sogen aub Eachien, wo lie ge=

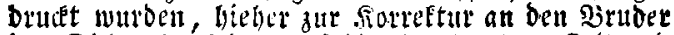

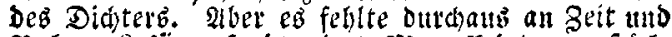

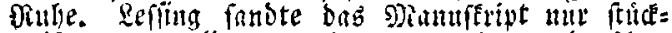
sveife nach Berlin; Sianterỉ Bemertungea barüber,

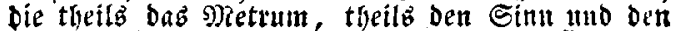

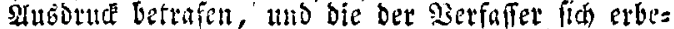

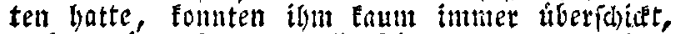
nod) seniger Eonuten alle feine gattwoiten abge= wartet uersen. So erEliren fid gentgrinm die

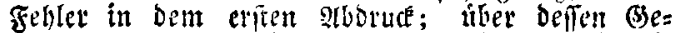

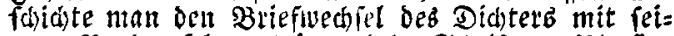
newn Bruber febe: Saimmttidie Edriften, 30. 3o, 5. $47 \mathrm{fu}$ folgg.

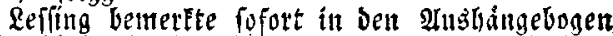
einige biefer Fehler fitt: eine neue glügabe, befferte atth bin und wieber, $z$. $B$. mande fedrbfübige Gamben, unt anderes. Dod war er hiberlaatur nitdit Jun Sorreftor geboren; atch, wein er ein

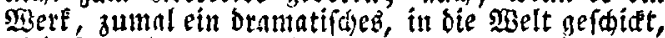
gleid)(am abgenadjt, lyatte: pifegte er es niddt gern 
balb wieber antufehen, vorzughlid bamalb, wo et mit andern 2rrbeiten vollauf beftaftigt war; obgleich er

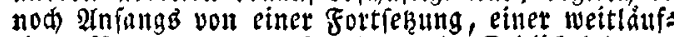
tigen sorrede, $\mathfrak{n}$. m. d. gl. furad. Eublí lebte er nidit cinntal mebr zuei volle Gafle (bib gebruas 2781). - Die Benubung jener Henderungen muste indes riditigete uno beflere Rebarten geben; und

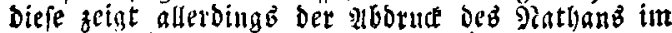
18ten Banbe feinter Sdriften (oom 's. 1793). Fur fiito eine gienge offenbarer Edreib = und Drud"s febler ftehen geblieben, die Den Eim entiftlen, wenigiteng verounteln. Detger nod) ît es, Dap̃

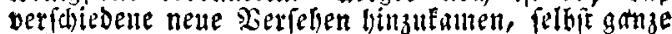
giobter aubigelafien wurben, wobuth vierfibige

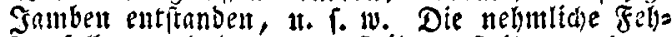
Iev fallen atth ben, von seit zu seit gemad)ten, cinzelnen 2ubritcen Deg (B)

(Segentwirtig bat man geitrebr, diere fleden zat vertilgen. Es fino melyere jener aboride vergliten worben, vorgüglid aber bie zuerît erwálinte Drigi=

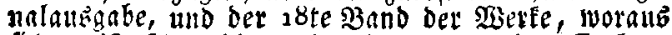
fich meit folson bie wable Resart ergab; offenbare

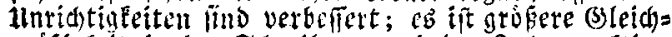

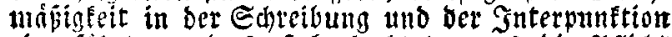
eingefultst, und fonit beobaditet, was bie piflicht

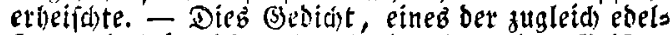

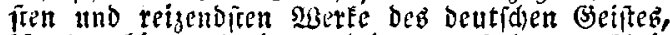
if es wohl wertis, in gereintigter Geftalt zll ericheis

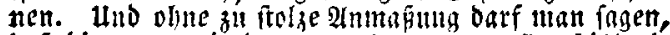

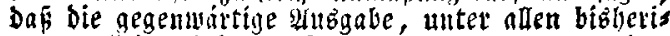
gen, alletil einigeratapen forreft genannt werben taint.

Berrin, Menjaljt 1813. 